CSID Working Paper Series

\#CSID-2013-001

\title{
A Multi-Method Approach to Study Robustness of Social-Ecological Systems: The Case of Small-Scale Irrigation Systems
}

\author{
Marco A. Janssen \\ Arizona State University, USA \\ John M. Anderies \\ Arizona State University, USA
}

January 7, 2013

The Center for the Study of Institutional Diversity resides in the School of Human Evolution and Social Change at Arizona State University. CSID can be found on the internet at: http://csid.asu.edu. CSID can be reached via email at csid@asu.edu, 


\title{
A Multi-Method Approach to Study Robustness of Social-Ecological Systems: The Case of Small-Scale Irrigation Systems
}

\author{
Marco A. Janssen ${ }^{a}$, John M. Anderies ${ }^{b}$, \\ ${ }^{a}$ Center for the Study of Institutional Diversity, Arizona State University, Tempe, AZ 85287-2402, USA; \\ ${ }^{b}$ Center for the Study of Institutional Diversity, Arizona State University, Tempe, AZ 85287-2402, USA;
}

Corresponding author:

Marco A. Janssen

School of Human Evolution and Social Change

Center for the Study of Institutional Diversity

Arizona State University

PO Box 872402

Tempe, AZ 85287-2402, USA

Marco.Janssen@asu.edu

\begin{abstract}
:
Elinor Ostrom was a leader in using multiple methods to perform institutional analysis. In this paper we discuss how a multi-method approach she pioneered may be used to study the robustness of social-ecological systems. We synthesize lessons learned from a series of studies on small-scale irrigation systems in which we use comparative case study analysis, experimental methods in lab and field settings, and mathematical models. The accumulated insights show the importance of creating institutional arrangements that fit the human ecology within the biophysical constraints of the system. Critical for success is the ability to maintain trust relationships, low levels of inequality and low transaction costs of coordination. Those systems that can leverage biophysical characteristics to help address challenges of monitoring, sanctioning, and coordination have an even higher chance of success.
\end{abstract}




\section{A Multi-Method Approach to Study Robustness of Social-Ecological Systems: The Case of Small-Scale Irrigation Systems}

Marco A. Janssen ${ }^{1}$ and John M. Anderies ${ }^{2}$

\section{Introduction}

Elinor Ostrom (1933-2012) was instrumental in developing a research agenda on the study of social-ecological systems and an exemplar in conducting interdisciplinary multi-methods research. In this article we reflect on her contributions and our collaboration with her in our work on robustness of social-ecological systems.

Ostrom started her study of resource governance at a time when interest in environmental issues was rising in society, but when approaches to developing solutions where based on theoretical or ideological grounds rather than on empirical studies. Especially influential was the essay by Garrett Hardin (1968) on the tragedy of the commons. Hardin lamented that when people share a common resource, the only ways to avoid overharvesting is to institute governmental regulations or allow for privatization of the resource.

The essay of Hardin (a biologist) was supported by influential work by economists Gordon (1954) and Scott (1955), and political scientist Olson (1965) and was rooted in rational choice theory. A key assumption was that actors made rational decisions based on selfish motives. The implications for policy were clear. Where practical, such as with some types of environmental pollution, top-down government regulation of firms was required. In other cases where monitoring and sanctioning is very costly, to avoid overharvesting of common resources it is critical to establish private property rights or tax the use of the commons.

If Hardin and his colleagues are right, why are so many common resources not overharvested? Elinor Ostrom (1965) observed in her dissertation work cases of farmers being institutional entrepreneurs in creating institutional arrangements to avoid overharvesting of aquifers. Her field work showed that Hardin's thesis does not hold for all systems. Over the decade following the completion of her $\mathrm{PhD}$ thesis, she conducted research on policing and governance of

\footnotetext{
${ }^{1}$ Center for the Study of Institutional Diversity, School of Human Evolution and Social Change, Arizona State University

${ }^{2}$ Center for the Study of Institutional Diversity, School of Human Evolution and Social Change and School of Sustainability, Arizona State University
} 
metropolitan areas to test the functioning of polycentric governance systems. During that time, she began performing comparative analysis among metropolitan areas to identify attributes of institutional arrangements that lead to better performance. She observed a wide array of different types of rules and started to identify structure in the data by developing more careful and consistent definitions. This led in the 1980s to the beginnings of the Institutional Analysis and Development (IAD) Framework (Kiser and Ostrom, 1982; Ostrom, 1986). The framework was built on well-defined components including the action situation, positions, outcomes, rules, etc. By providing a theoretical framework for the more systematic study of institutions, comparative analysis could better contribute to an accumulation of knowledge and theory development.

In the mid 1980s, she started to work on natural resources again. A group of scholars from different disciplines who had undertaken field studies during that period began to discover that the empirical evidence they were accumulating was not consistent with conventional theory (McKay and Acheson, 1987). They became concerned about the dominance of the conventional theory and the consequences of policies of privatization and nationalization that were becoming increasingly common in the management of natural resources. In order to understand the diversity of outcomes from individual case studies there was a need for synthesis. This happened through meetings of the National Research Council starting in 1983. A large number of case studies were discovered that showed both successes and failures of self-organized governance by resource users. The resources included local fisheries, irrigation systems, pastures and forests. In order to organize the case studies, this group started to draw on the IAD framework as a common language to compare the many case studies and develop a common data base.

Since 1985, Elinor Ostrom and a group of students and faculty affiliated with the Workshop of Political Theory and Policy Analysis started to systematically code case studies resulting in about 100 detailed coded case studies of fisheries and irrigation systems (the data for these case studies is now freely available at seslibrary.asu.edu). In her 1990 book "Governing the Commons" Ostrom provided an initial analysis of this meta-data (Ostrom, 1990). Originally the goal was to discover institutional arrangements that would lead to the best outcomes regarding the governance of common-pool resources. Despite her efforts to find such a golden rule, Ostrom was unsuccessful. Instead, she offered a number of 'design principles' as hypotheses of stylized facts observed in many case studies. These design principles included "well-defined boundaries", 
"monitoring", "conflict-resolution mechanisms", and "graduated sanctioning". These proposed design principles have held up the test of time (Cox et al., 2010).

Beginning the mid 1990s Ostrom became more immersed with ecological concepts and worked more closely with ecologists. For example, she became part of the board of the Beijer Institute for Ecological Economics in Stockholm, Sweden, and became more involved with the Resilience Alliance, an international organization focused on the study of social-ecological systems. Although Ostrom (1990) identified attributes of commons governance that can explain successes and failures, the basic framework was static. Ecologists such as C.S. Holling (1973) emphasized the resilience of ecological systems, which refers to the capacity of ecosystems to absorb disturbances and recognize to retain similar dynamic functions.

The rest of this paper deals with the study of the robustness of social-ecological systems, the topic on inquiry we collaborated with Ostrom. We explain below how robustness differs from resilience. We illustrate the concept of robustness and the use of the robustness approach mainly with case studies of small-scale irrigation systems. In fact, those small-scale irrigation systems function as our equivalent of the fruit-fly in evolutionary biology to illustrate robustness of social-ecological systems. Social-ecological systems consist of built infrastructure that connects actors to the ecology and connects the ecology to the social dynamics that play out among actors at different levels of organization. There is a huge variety of present-day small-scale irrigation systems around the world as well as multiple examples from the past that we can draw on. As such, irrigations systems are ideal systems on which to test our concepts.

We will begin with a discussion of the early work of Ostrom on small-scale irrigation systems which, under the right conditions, can be exemplars of self-governance. We will then introduce our robustness framework and illustrate how it has led, and may lead to new theoretical insights. Finally we discuss how theoretical questions that have emerged from the application of the robustness framework to case studies have led to recent lab and field experiments that have focused on the micro-foundations of decision making in irrigation dilemmas. By taking the reader through an example of the multi-method approach pioneered by Ostrom and developed further by Poteete et al. (2010), we illustrate the value of a multi-method approach for the study of social-ecological systems. Specifically, we show why the initial case-study-based research was rather limited for addressing questions related to robustness. We then illustrate the use of mathematical models and experiments to study underlying mechanisms that affect robustness in 
more depth. Finally, we discuss how moving back and forth between different methods generated new insights into the original case study research.

\section{Small-scale irrigation systems and collective action}

Irrigation systems have to solve two related collective action problems: 1) the provision of infrastructure necessary to use a resource (the physical irrigation infrastructure itself) and 2) the asymmetric common-pool resource dilemma in which the relative positions of "head-enders" and "tail-enders" generate asymmetric access to the resource (Ostrom and Gardner, 1993). If actors behave as rational, selfish economic agents, it is to be expected that no contributions to the infrastructure are made. Even if the challenge of provision of infrastructure was solved, there remain incentives for users to over-appropriate from the resource it generates. This is especially likely in irrigation systems where asymmetry causes some users to have privileges over other users; the head-ender who has first access to water may not necessarily share with the tail ender. Despite these challenges, there are many self-organized irrigation systems that exist and persist for very long periods (Hunt, 1988; Lansing, 1991; Ostrom, 1992). The study of governance of irrigation systems is therefore an important topic in our understanding of governance of socialecological systems in general.

Within the domain of irrigation systems we focus on small-scale irrigation systems that typically have a long history of self-governance, not the large scale engineered irrigation systems that often do not lead to productive outcomes. In fact, comparative studies (e.g. Lam, 1998; Shivakoti and Ostrom, 2002) show that farmer-managed irrigation systems achieve higher performance than agency-managed irrigation systems. Performance is measured by the physical condition of the system - how well maintained is the infrastructure; the technical efficiency of the system - does the water reach the tail end of the system; and agricultural productivity - what is the cropping intensity achieved. This difference is remarkable since agency-managed irrigation systems have typically more modern infrastructure. However, agency-managed systems often were not developed with an effort to clarify the water rights and management regime used by the farmers. Hence there was often a misfit between the existing institutional arrangements and the provided physical infrastructure that was hard to overcome.

Although small-scale irrigation systems might be perceived to be constructs from the past, they are still of critical importance for food security of a major part of the world's poorest 
people. In fact, nearly 90\% of farms worldwide are less than 2 hectares (McIntyre et al., 2009), and a large proportion of these rely on irrigation which consumes an estimated $70 \%$ of global developed water supplies (Barker and Molle, 2004) and produces 40\% of global agricultural commodities from $17 \%$ of global cropped area (Wallingford, 1997). It is likely that such smallscale farming systems will continue to provide the majority of food in developing countries for decades to come. Further, there is an emerging trend in many countries toward localizing some agricultural and food production (Pretty, 1999; Lyson, 2004). Such modern efforts may learn valuable lessons from the centuries of experience embodied in small-scale irrigation systems around the world.

Specifically, these small-scale irrigation systems have become exemplars of effective selfgovernance. Many are successful in addressing the challenges of governing shared resources over a long time and have been able to persist and adapt to perturbations and change (Ostrom, 1990). This past success involved becoming well-tuned to particular disturbance regime. Climate change is exposing farming systems to disturbances at a pace not previously experienced in human history (Thornton et al., 2009), fundamentally changing when, and how much water is available. In Pakistan, there is already a 10 to $15 \%$ decrease in precipitation in arid areas and rainfall, particularly during the summer monsoon, is expected to increase (IPCC, 2007). This means that at the beginning of the growing season when farmers most need it there will be less water availability, and when they need it least, there may be flash floods that destroy irrigation head works. In this sense, the disturbance regime to which these systems have become adapted will fundamentally change. Furthermore, globalization affects the incentives farmers face when choosing to invest immense effort in low earning farming practices compared to alternatives in an increasingly urbanized world. Globalization also affects which crops, including more resource intensive cash crops, are desired for production. As such these systems are exposed by processes that can make the iconic examples of self-governance be vulnerable to new challenges.

\section{A robustness framework for social-ecological systems}

The authors met Elinor Ostrom during at a workshop of the Resilience Alliance at the Royal Swedish Academy of Sciences in Stockholm, Sweden, in September 2000. The workshop was entitled "An overarching framework for modeling integrated ecological-institutional-economic 
systems." This was the beginning of a long-term collaboration that focused on the robustness and governance of social-ecological systems.

Our original goal was to apply the concept of resilience to the governance of social-ecological systems. However, we found that resilience can be difficult to apply to systems in which some components are consciously designed. Resilience typically refers to endogenous processes within a given system of interest and does not address normative considerations associated with incentives and decisions that were central to our research interests. We felt we needed a different set of concepts and tools.

Besides being involved with the Resilience Alliance, we also were involved with a series of workshops on Robustness at the Santa Fe Institute, New Mexico, USA. At those workshops physicists and engineers discussed their work on robust control, in which feedback systems are designed that make trade-offs between performance and robustness (Csete and Doyle, 2002). Robustness does not come without costs. In fact, making a system more robust to expected disturbances can make the system vulnerable to unknown disturbances. Therefore a system can be robust, yet fragile (Carlson and Doyle, 2002). We found these to be important insights from control systems research, since our interest in irrigation systems confirmed this notion of shifting vulnerabilities despite efforts to improve robustness.

We favor the use of the robustness terminology for an institutional approach to the study of social-ecological systems. Although institutional arrangements might not always be crafted from a robustness perspective, they are a set of rules that are intentionally designed. Furthermore, actors need to make tradeoffs regarding which components of the system in which to invest.

In a social-ecological system, social and ecological components are continuously interacting (Figure 1). Anderies et al. (2004) distinguish four key interacting components: the resource, the resource users, public infrastructure providers, and public infrastructure. The framework was developed to address questions regarding common-pool resources and public goods. Thus, private infrastructure, e.g. private land, knowledge, machinery, are not made explicit. Rather, they are implicitly included in the characteristics of the resource users.

For small-scale irrigation systems the common-pool resource is water. Resource users are farmers using water to produce crops. Public infrastructure providers are those members of a council who design and craft the institutional arrangements for governing the common-pool resource. In fact resource users often cope with operational rules, while public infrastructure 
providers often make decisions at the collective choice level. Note that "resource users" and "public infrastructure providers" refer to positions, not people. A single person can act (occupy the position of) both as a farmer and a water council members. Public infrastructure refers to the creation of built infrastructure such as head gates, dams and canals, as well as the institutions and organizational structures that enable monitoring and sanctioning of rules in use and collective choice processes.

Figure 1 shows the interactions between the components. For an irrigation system, linkage 1 refers to the extraction of water from the irrigation system by the farmers for growing crops. The amount that farmers can extract depends on the public infrastructure (links 4 and 5). Often a local water council decides on the rules regarding when and who shall receive water, and in what amount (link 3). Such councils often have input from the farmers (link 2) and in many cases the council consists of representatives from the farmer community. The outcome of collective choice processes affects the state of the irrigation system (link 3) and the enforcement of the water allocation rules. The public infrastructure also affects the level of the resource available due to the quality and state of repair of the irrigation system (link 4). The flow of water available from the irrigation system is further affected by the public infrastructure due to flow dividers in the canal system and enforcement of water allocation rules (link 5). A critical link in the success of social-ecological systems is the co-production between resource users and official enforcement mechanisms (link 6). For example, self-monitoring and enforcement lower the costs of enforcement and increase the effectiveness of institutional arrangements.

Arrows 7 and 8 refer to external perturbations, such as changes in water supply, temperature, pest outbreaks (arrow 7), and changes in external regulations, crop prices, input prices and political stability (arrow 8). In the study of robustness of social-ecological systems we are interested in the design features of Figure 1 which increase the robustness of the socialecological system. We find that link 2 is an especially critical connection since it affects the inclusion of local knowledge and acceptance of institutional arrangements designed by the public infrastructure providers. In the next section we will illustrate with a specific example how the specific implementation of links 1,4 and 5 also plays a critical role in the robustness of smallscale irrigation systems. In fact, in our example, for the social-ecological system to be well-tuned to the complex disturbance regime it faces, a specific design of these links is needed. This is likely true in general. 


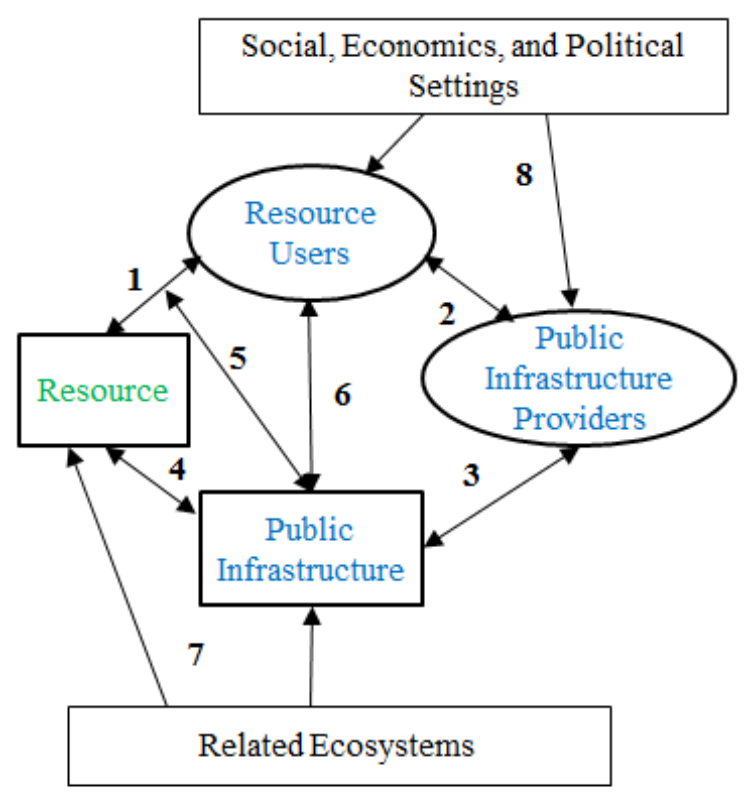

Figure 1: A conceptual model of a social-ecological system (based on Anderies et al. (2004)).

\section{Robust control applied to traditional irrigation systems}

Cifdaloz et al. (2010) apply the robustness framework to a traditional irrigation system, namely the Pumpa in Eastern Chitwan in Nepal. The farmer-managed irrigation system was started in 1968 by migrants and serves 140 households who own 70 hectares of agricultural land. There are six irrigation sectors, each with 20-25 households, with varying water right seniority (the sectors were labeled from 1 to 6 with 1 being the highest seniority). Based on qualitative and quantitative data from field work, a formal model was developed which consists of basic representations for water flows in the canals, the hydrological dynamics of water on fields, the connection between institutional arrangements and flow rates in canals, and the relationship between yield and water levels in each sector. The formal model allows us to apply concepts from robust-control in engineering to analyze the performance and robustness properties of this small-scale irrigation system.

The farmers in the Pumpa system utilize a set of institutional arrangements that affect when to open and close gates to divert water for the fields. Farmers adapt institutional arrangements based on two factors: the flow rate of the Pumpa river, and the functioning of the headgate infrastructure. Given the water availability in the Pumpa during the year, the required water for 
rice crops over the growing season, and the capacity of the community to repair flood damage to headgate infrastructure, the formal model was used to assess the impact of water variability on rice yields - both in terms of overall amount and equity of distribution. The impact of different institutional arrangements governing water distribution used by the farmers could be assessed in terms of how they affected the robustness of the system.

Depending on conditions, farmers use one of 4 water governance regimes: open flow - all main flow controls are open and sectors can take water as they please; sequential - sector 1 has full access to all water in the system until its needs are met, then sector 2, etc.; 12-hour rotations: sector 1 receives water for 12 hours, then sector 2, etc.; 24-hour rotations: sector 1 receives water for 24 hours, then sector 2, etc. When water availability from the river is normal, the model predicts that the open flow and 12-hour rotations are best. They both result in the same yield but open flow requires less effort and, not surprisingly, is what the farmers actually do. However, if water availability is decreased by half, those strategies lead to a catastrophic drop in yield, and a sequential policy of delivering water leads to better results. And the actual local policy of switching from open flow to sequential matches model predictions of Cifdaloz et al (2010). Further analysis shows that robust control predicts what farmers actually do in response to changing environmental conditions. In fact, the authors note that the this research illustrates an important linkage between formal modeling and case-study research. By virtue of their simplicity, stylized models often uncover the core drivers of the dynamics. In this case, the model suggested that 12- and 24-hour rotations should never be used. Yet, they were. This caused the research team to return to the case-study to gather new data in order to understand model predictions. It turned out that 12- and 24-hour rotations are only used in very specific circumstances. When checked, the model predicted 12- and 24-hour rotations would be best for these circumstances.

The strong agreement between what the model predicts farmers should do and what farmers actually do hints at the nature of the relationships among resource users, the resource, and public infrastructure in Figure 1. There is a tight connection between public infrastructure and the water resource. In fact, the institutional arrangement of a well-functioning irrigation system is highly optimized for the existing disturbance regimes. By highly optimized, we mean very finely tuned as, for example, the use of 12- and 24- hour rotations suggests. Changes in distribution of water during the year, for example due to climatic change, may have major performance consequences. 
For example, a shift in the timing of monsoons on the order of 3-4 weeks may be the most critical issue for the Pumpa system as it can reduce output by 50\%. Given the rigidities such as those occurring in existing small-scale irrigation systems, investment directed at discovering new ways to use the resources, water and soil, which are consistent with existing institutions or which require institutional adjustments that are possible within the existing institutional context would likely be more effective to increase food security compared to improving the performance of the physical infrastructure.

\section{Understanding decision making in irrigation dilemmas}

The robustness analysis above illustrates that robustness of small-scale irrigation systems is largely dependent on decisions actors in the social-ecological system make given the biophysical constraints the community faces. The type of analysis discussed above is a system-level view: how well does the system perform given that actors make particular decisions? In real systems, while the biophysical constraints can be modeled reasonably well, the same cannot be said of human decisions. Above, it is assumed that actors follow the rotation rules perfectly. This is not the case in real systems. Thus, to fully understand the robustness of SESs, we must move the analysis from the system-level to the individual level and try to understand how sensitive individual decisions are to a range of contextual variables. This is critical: even though a particular system of resources and public infrastructure combined with de jure institutions should be robust, it may be very sensitive to variation in human behavior that deviates from the de jure rules. In this section we illustrate how we use lab and field experiments to improve our understanding of the decision making of individuals in irrigation dilemmas. Although such experiments are abstract, they can provide a micro-level foundation for developing a more formal theory of social-ecological systems.

Lab and field experiments have been used for decades to understand collective action in commons dilemmas (Poteete et al., 2010). Experiments discussed below try to capture key features of irrigation systems in the experimental design, notably the asymmetry of access to the water resources. We first discuss experiments performed in the field with farmers in Thailand and Colombia (Janssen et al., 2012), and then present results of lab experiments where the system experienced disturbances (Anderies et al., in review). 
Janssen et al. (2012) presents experiments of an irrigation game were participants have positions A, B, C, D or E. The experimental design was motivated by case studies, i.e. the actual Pumpa system (and many like it) which have on the order of 5 sectors ordered upstream to downstream. Experiments are performed with pencil and paper, using tokens as the unit in which decisions are made. Decisions are made in private and tokens represent monetary value paid out in private at the end of the experiments. Participants earn one to two days of wage income for a 3 hour exercise, depending on the decisions they make.

Participants first have to make a decision regarding how much of the 10-token endowment they invest in the public infrastructure. A nonlinear production function is used to mimic the characteristics of a public good. The production function leads to a doubling of the tokens available for the group if everyone invests all their tokens. However, if only 20 tokens are invested, only 20 units of tokens are generated. Hence at least three of the five participants need to invest in the infrastructure to benefit from the irrigation system.

In the second decision participants make, a certain amount from the common resource is collected. For example, if the common resource has the size of 75 tokens (tokens represent water in an irrigation system), how will this be distributed among the participants? A has the first choice to harvest water from the common resource. Then B has the next turn to harvest water from whatever amount was left by A, and so on. The location of the five players is randomly determined before the first round and remains fixed over the first set of ten rounds of the game.

The experiment captures the dilemma of upstream participants who need the contribution of downstream participants to maintain the structure of their public infrastructure, which is crucial for the production of water in the game. However, the downstream participants can only obtain benefits from the shared water resource if upstream participants avoid the temptation to deplete the water resource and leave little water for downstream players.

If participants are selfish and rational, a game-theoretical analysis predicts that no participant will invest in the public infrastructure and all will keep their initial endowment for each of the 10 rounds of the experiment. In practice, however, participants invest on average 5 units in the public infrastructure. This investment level stays relatively stable, on average, over the rounds. Furthermore, the average contributions to the infrastructure are independent of the positions of the participants. There is substantial inequality of resource extractions among the participants in different positions. Participants in position A collect on average 18 tokens per round, while this 
drops to less than 3 tokens for position E. The difference in distributions of contributions to the public infrastructure and resource extraction suggests that a certain level of inequality of extraction is tolerated by the participants and that there may be some motivation behind contributions to the public infrastructure beyond individual gain.

In subsequent statistical analysis of the dynamics of the investments in public infrastructure and resource extraction reveals that the initial levels of investment correlate with the trust participants have in members of their village. The changes in investment levels are correlated to the level of inequality of extractions in the previous round. Hence higher levels of inequality of resource extraction lead to a reduction of investments at the group level. As such, equality and trust are key factors in explaining the dynamics in the irrigation game.

In lab experiments we use undergraduate students as our participants who have no experience with irrigation systems. However, lab experiments enable us to use computer based experiments that can cope with more complexity than paper and pencil experiments. The experiments reported in Anderies et al. (in review) do again have 5 participants in positions A (= upstream) to E (= downstream). Participants are endowed with 10 tokens in each round that they can invest in the public infrastructure. In contrast to the paper and pencil game, the infrastructure does not completely disappear after each round, but is reduced by 25 tokens out of a maximum level of 100 tokens. Hence the participants need to invest to maintain the infrastructure.

After investments are made, the participants have 50 seconds to grow a crop by opening and closing their gates. Even if the public infrastructure is in perfect condition, there will not be enough water for all participants to maximize crop output. As a group, the best outcome results if each participant extracts $60 \%$ of the level of water that would generate the optimal output at the individual level. At the beginning of each round before making decisions concerning investments and growing crops, participants can send text messages to one another in a chat room for 40 seconds. This allows the participants to coordinate and strategize on the decisions they make and the actions they take.

In Anderies et al. (in review) four scenarios are tested. Two scenarios include water supply variability. The default water level was 30 units per second, while the moderate variability scenario the water supply in the river varies between 25 to 35 units per second with a mean of 30 over the ten rounds, and in the high variability scenario, the water supply in the river varies between to 20 to 40 units per second with a mean of 30 over the ten rounds. Depending on the 
state of the public infrastructure, some proportion of those levels of water supply can be delivered to fields. Hence participants may overinvest in the infrastructure if the water level in the river is low in a particular round. The water supply level is announced after the investment decisions are made. The last two scenarios address declines in infrastructure capacity (headgate washout due to a flood event). The default level of infrastructure decline is 25 units per round, but in the low variability scenario, this level is between 15 and 35 units with an average of 25 over the ten rounds. In the high variability scenario the level of infrastructure decline is 80 units for some rounds, and 10 units for others, again with an average of 25 over the 10 rounds.

The experiments we performed included a baseline scenario in the first 10 rounds without variation followed by 10 rounds played with one of the four scenarios of environmental variability. The results show that, like the field experiments, inequality of resource extraction among participants has a significant impact on the level of investments. In the rounds with variability, groups who experienced a high level of inequality of resource extraction when there was no variability have a significant reduction of performance. Hence, inequality during periods of stability reduces the level of collective action when there is a disturbance when more cooperation is needed. If this finding indicates a more general insight, it predicts that small-scale irrigation systems with the same biophysical structure and average level of production but with higher levels of inequality of wealth and resources will be less robust to environmental variation and will experience more challenges to adapt to climatic change. This hypothesis is momentarily being investigated in a new project with field experiment.

\section{Discussion}

The natural resources that provide food and fiber for people around the world are predominantly managed at small scales. Most farms around the world are less than 2 hectares and are family managed. Shared infrastructure and governance are typically provided by local communities where the number of households in on the order of tens to hundreds. Top-down interventions in these systems have often failed. This begs the question: how will food and fiber production systems around the world cope with global change? Are these small scale systems robust enough to cope with the climate change as well as the social and economic change they will 
face? How should governments invest to increase the adaptive capacity and robustness of these systems? How might such investments aimed at increasing robustness to a set of perceived risks introduce hidden fragilities? These are all important questions for global change policy.

The complexity and diversity of resource systems around the world and the range of uncertainty they face is beyond the capacity of central governments to manage. We should expect that local knowledge and the capacity for self-organization will be important for the management of natural resources. Small-scale irrigation systems are iconic exemplars of selfgovernance, and thus provide a model system for studying the broader challenges all resource systems face. The comparative studies of Elinor Ostrom on long-lasting case studies of common pool resources provided numerous examples of such irrigation systems. Her work on these systems has generated many important insights regarding factors that contribute to successful self governance. The extension of this work on governance to the dynamics of SESs discussed here highlights the subtle challenges to governance regimes experiencing novel change. Changes in the disturbance regimes due to climatic change and globalization makes these smallscale irrigation systems vulnerable. In fact, basic principles from robust feedback control suggests that they might have become highly tuned to the disturbance regimes they faced in the past which makes them vulnerable to unexpected changes.

Our broad discussion of our research over the last 10 years highlights the importance of transdisciplinary work using different methods. We rely on ethnographic case study descriptions, comparative case study analysis, formal mathematical modeling, and lab and field experiments to pursue our questions. Elinor Ostrom was not only an exemplar for transdisciplinary work but also in crossing methodological silos in order to advance her research. The research questions are central, and being open to new approaches may lead to new discoveries.

Our encounters with electrical engineers who are specialists in robust control have delivered to us a new perspective on governance of social-ecological systems. Within our community of resilience scholars, resilience was an endogenous attribute of a system which could be disturbed by human activities. Engineers develop mechanical systems such as airplanes in which they must to design control systems to cope with known disturbances; they cannot rely on poorly defined notions of "adaptive capacity" and "adaptive learning" to cope with uncertainty and change. A critical lesson is that robustness comes at a cost and one has to make tradeoffs between system performance and robustness and between different vulnerabilities. Increasing robustness to one 
type of disturbance may increase vulnerability to others. Such a deliberation is of critical concern in the creation of institutional arrangements that aim to govern the sustainability of socialecological systems.

At present, we lack a good understanding of how people make decisions in complex systems. As a result, we have start pursuing a research program focusing on lab and field experiments to enhance the micro-level theoretical foundations for the study of social-ecological systems. In contrast to typical experiments on the commons pursued by economists or psychologists, we include explicit ecological dynamics. The irrigation games show the critical role of trust and inequality. In periods of stability the performance of irrigation systems may be similar, but our experiments indicate that inequality of earnings may reduce the adaptive capacity of the community to changes in the disturbance regime. This hypothesis is now being tested in a new series of experiments and field work in various countries.

Small-scale irrigation systems serve as a fruit fly in the study of the dynamics of socialecological systems. Their diversity and complexity provides numerous analogies to larger scale social-ecological systems. When we apply multiple methods to this rich range of cases, we can develop basic principles that govern the dynamics of social-ecological systems and their capacity to cope with change, much in the same way the fruit fly is used to understand basic principles of evolution. As such our initial findings on the importance of robustness tradeoffs (from combining case-study analysis with dynamic modeling and robust control) and the role of trust and inequality (from human subject experiments) may provide lessons for governance of sustainability in general. A strong theme that emerges from all of our work is that in order to address our ability to cope with an increasing number of environmental challenges, we will also need to address increasing social and economic inequalities (Stiglitz, 2012).

\section{References}

Anderies, J.M., and M.A. Janssen (in review). "Robustness of Social-Ecological Systems: Implications for Public Policy."

Anderies, J.M. and M.A. Janssen (2011). "The fragility of robust social-ecological systems," Global Environmental Change 21: 1153-1156.

Anderies, J.M., M.A. Janssen, A. Lee and H. Wasserman (in review). "Environmental variability and collective action: Experimental insights from an irrigation game." 
Anderies, J., M.A. Janssen and E. Ostrom (2004). "A framework to analyze the robustness of social-ecological systems from an institutional perspective," Ecology and Society 9(1):18.

Barker, R. and Molle, F. (2004) Evolution of irrigation in south and southeast Asia. Technical report, IWMI. Comprehensive Assessment Research, No:5.

Bastakoti, R.C., and G.P. Shivakoti (2012). "Rules and collective action: An institutional analysis of the performance of irrigation systems in Nepal," Journal of Institutional Economics 8: 2, 225-246.

Carlson, J. M., and J. Doyle (2002). “Complexity and robustness,” Proceedings of the National Academy of Science 99 (suppl. 1):2538-2545.

Cifdaloz, O., A. Regmi, J.M. Anderies and A.A. Rodriguez (2010). "Robustness, vulnerability, and adaptive capacity in small-scale social-ecological systems: the Pumpa Irrigation system in Nepal," Ecology and Society 15(3): 39. [online] URL: http://www.ecologyandsociety.org/vol15/iss3/art39/

Cox, M., G. Arnold, and S. Villamayor Tomás (2010). “A review of design principles for community-based natural resource management," Ecology and Society 15(4): 38. [online] URL: http://www.ecologyandsociety.org/vol15/iss4/art38/

Csete, M.E. and J.C. Doyle (2002). "Reverse engineering of biological complexity," Science 295:1664-1669.

Hardin, G. (1968). “The Tragedy of the Commons,” Science 162: 1243-1248.

Holling, C.S. (1973). "Resilience and stability of ecological systems," Annual review of ecology and systematics 4:1-23.

Gordon, H.S. (1954). "The Economic Theory of a Common-Property Resource: The Fishery," The Journal of Political Economy 62(2): 124-142.

IPCC (Intergovernmental Panel on Climate Change) (2007). Climate change: Impacts, adaptation and vulnerability, contribution of working group ii to the fourth assessment report of the intergovernmental panel on climate change. Technical report, Intergovernmental Panel on Climate Change.

Janssen, M.A., J.M. Anderies and S. Joshi (2011). "Coordination and Cooperation in Asymmetric Commons Dilemmas," Experimental Economics 14(4): 547-566.

Janssen, M.A., F. Bousquet, J.C. Cardenas, D. Castillo, and K. Worrapimphong (2012). "Field Experiments of Irrigation Dilemmas," Agricultural Systems 109: 65-75. 
Kiser, L. and E. Ostrom (1982). 'The Three Worlds of Action: A Meta-Theoretical Synthesis of Institutional Approaches," In Strategies of Political Inquiry, ed. Elinor Ostrom, 179-222. Beverly Hills: Sage Publications.

Lam W.F. (1998). Governing Irrigation Systems in Nepal: Institutions, Infrastructure, and Collective Action. ICS Press, Oakland, CA.

Lyson, T.A. (2004). Civic agriculture: Reconnecting Farm, Food, and Community. Tufts University Press.

McCay, B.J. and J.M. Acheson (eds) (1987). The Question of the Commons : The Culture \& Ecology of Communal Resources, University of Arizona Press, Tuscan.

McIntyre, B. D., H.R. Herren, J. Wakhungu and R.T. Watson (eds) (2009). International Assessment of Agricultural Knowledge, Science and Technology for Development (IAASTD): Global Report. IAASTD.

Olson, M. (1965). The Logic of Collective Action: Public Goods and the Theory of Groups, Cambridge, MA: Harvard University Press.

Ostrom, E. (1965). Public Entrepreneurship: A Case Study in Ground Water Basin Management. (Ph.D. Dissertation, University of California-Los Angeles, 1965).

Ostrom, E. (1986). “An Agenda for the Study of Institutions," Public Choice 48(1): 3-25.

Ostrom, E. (1990). Governing the Commons: The Evolution of Institutions for Collective Action. New York, NY: Cambridge University Press.

Poteete, A.M., M.A. Janssen and E. Ostrom (2010). Working Together: Collective Action, the Commons and Multiple Methods in Practice. Princeton, NJ: Princeton University Press.

Pretty, J. (1999). The living land: agriculture, food and community regeneration in the 21st Century. Earthscan/James \& James.

Scott, A. (1955). "The Fishery: The objectives of sole ownership," Journal of Political Economy 63(2): 116-124.

Shivakoti G.P. and E. Ostrom ed., (2002). Improving Irrigation Governance and Management in Nepal. ICS Press, Oakland, CA.

Stiglitz, J.E. (2012). The price of inequality: How today's divided society endangers our future, Norton, W. W. \& Company, Inc.

Thornton, P., P. Jones, A. Alagarswamy and J. Andresen (2009). "Spatial variation of crop yield responses to climate change in east Africa," Global Environmental Change 19:54-65. 
Wallingford, H. R. (1997). Priorities for Irrigated Agriculture. Occasional Paper No. 1. Department of International Development, UK. 